\title{
How to return to subjectivity: Natorp, Husserl, and Lacan on the limits of reflection
}

Theory \& Psychology

\section{Jasper Feyaerts}

Ghent University

\section{Stijn Vanheule}

Ghent University

\begin{abstract}
This article discusses the recent call within contemporary phenomenology to return to subjectivity in response to certain limitations of naturalistic explanations of the mind. The meaning and feasibility of this call is elaborated by connecting it to a classical issue within the phenomenological tradition concerning the possibility of investigating the first-person perspective through reflection. We will discuss how this methodological question is respectively treated and reconfigured in the works of Natorp, Husserl, and Lacan. Finally, we will lay out some possible consequences of such a cross-reading for the conception of subjectivity and the concomitant effort to account for this dimension of first-person experience in response and in addition to its omission within the standard third-person perspective of psychological research.
\end{abstract}

\section{Keywords}

Husserl, Lacan, Natorp, phenomenology, psychoanalysis, reflection, subjectivity

In recent years we have witnessed a resurgence of the issue of subjectivity in different research domains ranging from cognitive (neuro)science and analytic philosophy of mind to psychopathology and the so-called consciousness studies. One of the central impetuses for this return to subjectivity is related to a growing awareness on the part of philosophers and scientists alike, working within these various related research domains, of a certain

\section{Corresponding author:}

Jasper Feyaerts, MSc, Department of Psychoanalysis and Clinical Consulting, Ghent University, H. Dunantlaan 2, B-9000 Ghent, Belgium.

Email: Jasper.Feyaerts@UGent.be 
dissatisfaction with what is widely considered to be the dominant paradigm in the theorization of the mind from the 1960s onwards: that is, cognitive science. Although it was initially expected that cognitive science would fulfill Hume's famous ambition to become "the Newton of mental phenomena," many researchers nowadays agree that some foundational issues still stand in need of further clarification (Parnas, Sass, \& Zahavi, 2013). Preeminent among these issues is the relation between, on the one hand, cognitive descriptions of the mind's functioning, typically conceived as some kind of "information processing" activity within our black box, responsible for generating various kinds of cognitive behavior and, on the other hand, subjectivity, loosely defined throughout the literature in the phenomenological sense as "what it is like" to be a cognizing mind, the way things are or appear from a subject's point of view. Moreover, the core of the argument that is raised against cognitive science is that it suffers from an "explanatory gap" vis-à-vis subjectivity; that although it has provided us with ever-increasing complex descriptions of the cognitive dimension of the mind "as it is in itself," it nevertheless fails to account precisely for how "this mind" appears to itself, how the functioning of the mind is experienced subjectively. Or, in the concise wording of Roy, Petitot, Pachaud, and Varela (1999), "explaining what is happening in [emphasis added] the black box is not explaining what is happening for [emphasis added] the black box" (p. 12). According to advocates of this explanatory gap argument, it is thus one thing to try to account for what is going on in our brain - at whatever level of explanation, whether neurobiologically or functionally defined - when we engage in various kinds of cognitive behavior (e.g., memory, perception, attention), and another thing to try to account for what appears or seems to be going on when we engage in those types of behavior from a first-person point of view. Hence, what the core of the explanatory gap argument vis-à-vis the current status of cognitive science amounts to can be succinctly formalized as follows: (a) cognitive science purports to give a complete account of the cognitive mind; (b) an essential feature of creatures endowed with such a cognitive mind is that they have the capacity for phenomenality: in clear contradistinction with tables or stones, there is something "it is like" to be a cognitive agent; (c) cognitive science does not attempt or (up until now) fails to account for this subjective dimension; and (d) hence, in its current status, cognitive science is incomplete and found wanting with respect to (a).

As a consequence, it has been argued repeatedly that a mere functional analysis of the inner workings of the mind does not provide an exhaustive nor an adequate explanation as long as the first-person dimension of subjective experience is not taken into consideration as an explicit area of investigation (Flanagan, 1992; Parnas et al., 2013; Strawson, 1997). In short, the phenomenological critique vis-à-vis current cognitive research practice is that - insofar as it is aiming at a full-fledged naturalistic explanation of the mindit has to take the subjective dimension seriously as a central part of the explanandum. If not, the whole naturalistic endeavor will be question-begging from the very start.

In light of this explanatory gap and the concomitant phenomenological argument, several authors have argued for a return to classical phenomenological approaches of subjectivity in hopes of enhancing our understanding of the relation between cognitive processes and their phenomenal manifestations (Gallagher, 2002; Gallagher \& Varela, 2001; Gallagher \& Zahavi, 2012). According to these authors, phenomenology, as originated in the work of Husserl and subsequently developed by, for example, Heidegger, 
Merleau-Ponty, and Sartre, could provide us with a refined theory and description of subjectivity as the necessary requirement prior to the effort of "bridging the gap." Leaving aside the delicate question of whether phenomenology could indeed take up a preconfigured role as a supplement to a naturalistic explanation of the mind (see De Preester, 2006; Rinofner-Kreidl, 2005; Zahavi, 2010), and rather than immediately assuming that phenomenology provides us with a clear-cut and unproblematic description of subjectivity which is hence ready to be transposed to other research domains, the purpose of the present article is to investigate some problems that reside within the phenomenological effort to investigate subjectivity itself. Moreover, we will revisit a classical problem in the phenomenological tradition with regard to the conditions for phenomenology as a first-person description of subjective experience related to the following question: is it possible to investigate subjectivity reflectively? This is how we will proceed.

First we will present Natorp's challenge to a phenomenological approach as a reflective investigation of subjectivity in his Allgemeine Psychologie nach kritischer Methode from 1912. According to Natorp's classical argument, every effort to grasp subjectivity by means of reflection is always a step too late vis-à-vis subjective experience as it is lived before this reflection. This will lead him to deny the possibility of attaining a direct access to subjective experience and to refiguring his method as a reconstruction with subjectivity hence considered as an unattainable limit-case.

Next we will explore Husserl's answer to Natorp's critique of reflective phenomenology as laid out in his Ideas Pertaining to a Pure Phenomenology and to a Phenomenological Philosophy (1913/1983). Contra Natorp, Husserl will defend the phenomenological method of reduction as being based on direct evidence concerning the description of lived experience in its intentional functioning. This method, Husserl claims in 1913, is in no way indirect or reconstructive, yet directly based on evidence as obtained in phenomenological reflection.

Finally, we will shed a new light on the debate between Natorp and Husserl concerning the status of phenomenological reflection by relating it to the distinction Lacan draws in his 11th seminar on The Four Fundamental Concepts of Psychoanalysis between "the subject of enunciation" and "the subject of the utterance" (1964/1977). As will become clear, Lacan's minimal conceptual apparatus is an alternative way of writing Natorp's and Husserl's ongoing debate concerning the relation between subjectivity and objectivity and as such it will prove helpful to tackle our question regarding the possibility of investigating subjectivity by means of phenomenological reflection and to lay out some consequences of this cross-reading for the contemporary debate on the explanatory gap and the consequent call for a return to subjectivity.

\section{Natorp's critical psychology: Subjectivation versus objectivation}

The main goal of the so-called Neo-Kantian Marburg School — with Cohen, Natorp, and Cassirer as its main representatives - was the further development of the transcendental project as initially laid down by Kant in his Critique of Pure Reason. In line with the Neo-Kantian project, the transcendental method was envisioned to elucidate, as the 
Marburgers called it, "the logic" of objective knowledge (Erkenntnislogik), in other words, it seeks to give a logical justification for the a priori conditions that govern the construction of objective reality through subjective, cognizing acts (Kim, 2007). According to this transcendental view, it is in science that objective reality is constructed through cognizing activities, whereas it is the proper task of transcendental philosophy to clarify the a priori conditions that govern this construction. More precisely, Marburg Neo-Kantianism set out from the fact of mathematized natural science (Cohen's Faktum der Wissenschaften, 1977), that is, science's progressive determination of an objective order as it is presumed to appear through or in sensible phenomena, via a method of hypothesizing laws that are "valid" (gültig) or "hold" (gelten) these phenomena, in order to inquire subsequently into the a priori conditions that factor into this construction of objective reality and which hence could explain how such a constructive determination is attained. As such, the goal of the Marburg logic was to determine, by means of an analytic reconstruction of thinking's synthetic construction of objectivities, how scientific thinking lawfully generates or synthesizes the unities that are its objects of knowledge. It is consequently in science's progressive objectifications that we can find subjectivity at work, where it is seized as the lawful activity in accordance with which the subsequent hypothesizing of science occurs.

The interesting addition of Natorp to this standard picture of the transcendental project and at the same time the problematic nexus running through both his Allgemeine Psychologie (1912) and his discussion with Husserl, is that not only cognizing activity in science is objectifying; subjective life as such is objectifying, whether it leads towards objective knowledge or not. According to Natorp, this becomes most clear in subjective enunciations in that they always claim some-thing. As such, every expression (Äußerung) is an objectifying externalization (Entäußerung) vis-à-vis subjective experience before the utterance (Natorp, 1912, p. 99). As Natorp explains, this is the character of "objectifying cognizing (Erkentniss), scientific as well as pre-scientific: ... to make objects out of appearances (Erscheinungen)" (1912, p. 193, our translation). But if it is characteristic for all reflections to make objects out of appearances, what consequence will this have on the study of subjectivity as such? If all subjective acts (reflection, judgments, enunciations, etc.) in one way or another objectify this pristine (ursprünglich) subjectivity, it is both obvious and inevitable that the acts pertaining to the study of subjectivity will be objectifying too. According to Natorp, whereas everything else can be made into an object (Gegenstand) of reflection, the subject as such eludes this reflection (nicht sich selber Gegenstand sein). The moment we start to investigate subjectivity reflectively, we transform it into its very opposite. Therefore, in reflection, the subject of consciousness necessarily makes way for an object of consciousness. ${ }^{1}$ Furthermore, according to Natorp, this transcendental clarification with regard to the limits of reflection has important repercussions for the discipline par excellence that ought to be devoted to the scientific study of subjectivity, that is, psychology. To the extent that psychology is a discipline devoted to disclosing scientific facts about subjectivity, it treats its object in the same objectifying way as other scientific disciplines do with regard to their respective objects of study and it will subsequently disregard the ontological difference that set subjectivity apart from objectivity. In so doing, the particular element that makes up for the subjectivity of the 
subject and that is concomitantly the actual raison d'être of psychology as a scientific field of study in the first place - the dynamic, concrete, fluctuating life of subjective experience - is lost. As Natorp adds in a Hegelian way, that which makes the subject a subject is "killed," mortified under its objectifying representations (1912, p. 191). All traditional psychology supposedly proceeds in this way: according to Natorp psychology "kills subjectivity in order to dissect it, and believes the life of the soul is on display in the result of the dissection" (1912, pp. 102-103).

So far Natorp's conclusion with regard to the possibility of investigating subjectivity has not been very optimistic. Since every effort to investigate subjectivity amounts to an objectifying Entäußerung of its point of departure, what other options do we have? The title of Natorp's 1912 work-Allgemeine Psychologie nach kritischer Methode - nevertheless seems to suggest that there is a "critical method," able to overcome the pitfalls of traditional psychology which merely deals with the subjective as a factual state of psychic affairs. Indeed, this is the task Natorp sets out for his "transcendental psychology." It became clear earlier that the method of this transcendental psychology should allow for a clarification of subjectivity that is not objectifying, one that doesn't construct an object out of subjective appearances. Hence, Natorp suggests we will never be able to do justice to the ontological difference if we operate within an object-oriented methodological monism, put differently: ontological difference should be met by methodological difference. Therefore, whereas, according to a transcendental perspective, objectivity is attained by a construction of objective idealities out of the immediate flux of subjective appearances, subjectivity should be investigated by going back from these objectifications to the immediateness of subjective appearances by a method of reconstruction. Methodologically speaking, reconstruction should therefore be regarded as the inverse method of objectification, the "turning inside out" (Umstülpung) of its constructive effects towards that from which reality is progressively built up in the first place: the concrete and dynamic conscious life of the subject (Natorp, 1912, p. 20). In a phenomenological vein, Natorp also speaks of the immediate in consciousness as "phenomena" and explicitly uses the term "reduction" for his reconstructive move:

Thus for all spheres, scientific representations as well as unscientific representations such as fantasy, but also the regions of feeling, desiring and willing, the same task is posed, [namely] that of a reduction of the always already and in some way or other objectified representation to the immediate of consciousness. (Natorp, 1888, p. 89)

To summarize, Natorp's insistence on the ontological difference between subjectivity and objectivity leads him to deny the possibility of investigating subjectivity in a reflexive and thus methodologically monist way. Since by necessity, reflection - and by extension every subjective act-follows the constructive path of objectifying the immediacy of fluctuating subjective phenomena, a direct description of subjective life through a reflective grasp is considered unattainable and therefore should be substituted for a retroactive subjectivation as a "reverse teleology" (Luft, 2010, p. 225). ${ }^{2}$ Ultimately, however, according to Natorp, the dimension of pure subjectivity as the immediacy of conscious phenomena remains an unreachable ideal and will hence forever elude our grasp (1912, p. 233). 


\section{Husserl's response: "The principle of all principles"}

One does not have to be an erudite phenomenologist to see that Natorp's methodological reservations concerning the possibility of a direct description of subjective experience through reflection depart significantly from phenomenology's modus operandi with regard to its field of study. A common way to define phenomenology is determining its task as a description of our lived experience as it is given, precisely in the way it is given, in its pre-theoretical immediacy. Indeed, as Husserl famously holds in his Ideas I: "the principle of all principles" which grounds phenomenology as an eidetic enterprise-as a pure description of the essential (eidetic) structures of consciousness-is that it builds upon that which is present "in self-giving evidence and intuition" (1913/1983, p. 44). Therefore, Natorp's challenge vis-à-vis phenomenology as a reflective investigation of subjectivity is leveled at nothing other than what Husserl-from the publication of his Logical Investigations (1970b) in 1901 onwards - considered its most basic methodological principle, namely that of reflexive intuition which brings phenomena to clear and apodictic evidence. As Husserl explains in the section, Critical Excursis: Phenomenology and the Difficulties of "Self-Observation," in response to similar challenges to his reflective paradigm as those raised by Natorp:

The phenomena of reflection are, in fact, a sphere of pure and possibly perfectly clear data. It is an eidetic insight [emphasis added], always attainable because immediate, that starting from the objectively given as objective reflection on the presentive consciousness and its subject is always possible: starting from the perceived, from what is "there 'in person'," a reflection on the perceiving; starting from the remembered, just as it "hovers before us" as remembered, as "having been," a reflection on the remembering; starting from the statement in the flowing off of its being given, a reflection on the stating [emphasis added], etc. It is evident that by virtue of its essence - ... something such as consciousness and consciousness-content ... is cognizable by reflection. (Husserl, 1913/1983, p. 187)

So for Husserl, the possibility of grasping subjectivity by means of reflection is indispensable for the methodological grounding of phenomenology to its subject matter. It is furthermore essential for, so to speak, properly essential reasons: reasons pertaining to the essence of consciousness itself as revealed in eidetic insight. Let us be precise here with regard to Husserl's more or less Cartesian argumentation: according to Husserl, it is "countersensical" to deny phenomenology's "principle of all principles" and thus also to doubt the givenness of subjective processes and their accessibility through reflection, since this doubt itself would again be asserted from the initial givenness of reflective intuition. Doubts concerning the possibility of a reflective investigation of subjectivity thus "always-already" presuppose knowledge of the so-called "reflectionally unmodified mental processes" which is at the same time and erroneously placed into question (Husserl, 1913/1983, p. 185). Consequently, the methodological critique concerning the possibility of reflective intuition culminates according to Husserl in doubting the possibility of claiming anything whatsoever on the basis of reflectionally presentive intuition and is thus essentially self-refuting. As Husserl contends:

All genuine skepticism of whatever kind and persuasion is indicated by the essentially necessary countersense that, in its argumentations, it implicitly presupposes as conditions of the possibility 
of its validity what it denies in its theses. ... He who also says: I doubt the cognitive signification of reflection, asserts a countersense. For as he declares his doubt, he reflects, and setting down this statement as valid presupposes that reflection actually and without doubt (scl. for the cases present) has the cognitive value doubted, that it does not change the relation to something objective, that the reflectionally unmodified mental process does not forfeit its essence in the transition to reflection. (Husserl, 1913/1983, pp. 185-186)

Phenomenology's methodological procedure of reflective intuition is in sum not a consequence of any strategic or methodological argumentation which transcends the stringent limits of "immediate intuition" within conscious experience, but is for Husserl essentially grounded and given as something obvious within the confines of absolute consciousness itself.

However, as might have become clear from the foregoing, the foundational principle that grounds phenomenology as a reflective investigation of subjectivity does not entail just any intuition. As Husserl explains: "Of course reflection can be effected by anyone and anyone can bring consciousness within the sphere of his seizing regard" (1913/1983, p. 114). Rather than simply directing the introspective gaze at ourselves and describing what is or is not presented there, phenomenology, by contrast, wants to disclose "a new region of being never before delimited in its own peculiarity" (Husserl, 1913/1983, p. 63). This new region of being, which will become the fundamental field of phenomenological investigation, is the field of "pure consciousness," "the sphere of being of absolute origins" (Husserl, 1913/1983, p. 129), which is allegedly only seized upon by phenomenological reflection. But now the obvious question suggests itself: if this purportedly new region of being is the field of consciousness, why not turn to the empirical findings psychology discloses about this object of study? In what way does this sphere of absolute consciousness differ from the region that is supposed to be already well known, that of the mind or the psyche, which is extensively dealt with by its own regional science, that of psychology? This is of course an important question for Husserl not least because he was especially concerned that phenomenology would not be confused with any kind of psychology whatsoever. Since Husserl's answer to this question is as wellknown as it is contested - especially in the discussion on the alleged (non)sense/(im) possibility of a naturalized phenomenology we briefly considered in our introductionwe will only sketch out the main points we will need for our present inquiry. The principal reason why, according to Husserl, "pure phenomenology is not psychology" (1913/1983, p. xix) has nothing to do with accidental delimitations of its field of study, that is, in the same way as "physics is not psychology" because it treats another "province of reality," nor is this faithful separation between phenomenology and psychology altered by the seemingly obvious fact that both have to do with consciousness. What prevents phenomenology from being reduced to psychology, an empirical science dealing with psychological "matters of fact," is that the latter merely deals with consciousness or subjectivity as real, actually existing occurrences belonging to real empirical subjects in the spatiotemporal world as absolute reality (1913/1983, p. xx). As such, psychology operates from within the naturalistic attitude wherein the givenness of the actual empirical reality of its object of study - in casu consciousness, psychic reality, behavior, ...-is always-already tacitly assumed and accepted as pre-existing in a world where things just are what they are, independent of the performative consciousness of the 
empirical psychologist as scientific investigator of Nature. It is mainly because of this attitude that Husserl turns away from what he calls "that philosophical poverty in which, under the fine name of a world view founded on natural science, we are vainly fatiguing ourselves" (1913/1983, p. 115). On the one hand, psychology is precisely a "philosophical poverty" because it only studies consciousness as a component part of Nature and does not reflect on the conditions of possibility of its givenness. Psychology merely takes this givenness of consciousness as an object of scientific inquiry for granted without effectively inquiring how this is possible, without answering the transcendental question of the constitutional conditions of its own object of experience, a question which is nevertheless indispensable for grounding and justifying its scientific activity. Or, to slightly reduce the foregoing formulations, psychology only treats consciousness as an object in the world, in the sense of a "part-whole" relation, and not as a subject for the world, in the sense of a "constituting-constituted" relation. We are, on the other hand, "vainly fatiguing ourselves" if the effort to present a phenomenological clarification of pure consciousness is once again confused with an investigation of Nature since the latter, as intentional correlate of meaning bestowing consciousness within the a priori correlation between "constituting subjectivity - constituted objectivity," depends for its sense as a transcendent objective unity precisely on the constitutional acts of pure consciousness. This does not mean however that something is "wrong" with psychology, nor with the other sciences that operate within this attitude, as long as we understand its scientific activity and its accomplishments as, indeed, always starting from and situated in this attitude. On the contrary, Husserl recognizes in this "uncritical presupposition" one of the pillars that carries the success of those sciences (Husserl, 1925/1997, p. 191). Husserl's point is simply that, when aspiring to understand the "general thesis" itselfthe experiential fact of there-being-a-world-for-us - psychology does not have anything to tell us, nor does any other science that studies objects in this given world. To schematize the foregoing argument: if it is (a) the task of transcendental phenomenology to understand the thesis of the naturalistic attitude - this is its explanandum - and if (b) the sciences always already operate from the presupposition and pre-givenness of this explanandum, then it follows that (c) phenomenology should avoid any reference to those sciences because otherwise (d) elements from the explanandum would reappear in the phenomenological elucidation of the explanans. According to Husserl, this would amount to what he calls "the transcendental circle, which consists in presupposing something as beyond question when in fact it is encompassed by the all-inclusiveness of that very question (Husserl, 1925/1997, pp. 249-250).

Thus, like Natorp, Husserl stresses the necessity of a radically different approach to consciousness, one that does not conflate subjectivity and objectivity but is instead able to reckon with this ontological difference on a methodological level. Since, from a transcendental phenomenological perspective objective reality is only possible and comprehensible as an intentional unity within the confines of a transcendentally pure consciousness, the phenomenological clarification of subjectivity should accordingly shift from an object-oriented to a subject-oriented investigation of consciousness. This is indeed the role to be played by, in a first movement, the famous phenomenological epoché through which the thesis of the natural attitude is "bracketed" or "put out of action" in order to avoid us relying on knowledge obtained within this attitude to tackle 
the question of constitution (i.e., on pains of the "transcendental circle") and to get a clear picture of the phenomenon that we would like to explain, that is, the world as it appears to me in my experience. However, in itself, the epoché does not explain anything with regard to the question of world-constitution. It is only, in Husserl's words, "the gate of entry through which one must pass in order to be able to discover the new world of pure subjectivity" (1970a, p. 260). Passing through that door, we have arrived at the second methodological movement, that of the phenomenological or transcendental reduction, through which we are led back (Latin: reducere) from the constituted world - as it manifests itself as object-pole within my intentional experience- to that "place" where the world constitutes itself in its givenness-for-me, that is, transcendental subjectivity. In this way, the world placed within brackets functions as the transcendental guiding clue (Leitfaden) starting from which the constitution-question can be pursued in a reflexive way:

Starting from the experiential world given beforehand as existent and ... from any experiential world whatever, conceived as given beforehand as existent, we exercised transcendental reduction - that is: we went back to the transcendental ego, who constitutes within himself givenness-beforehand and all modes of subsequent givenness. (Husserl, 1960, p. 136)

To summarize: according to Husserl, an adequate, reflective description of subjectivity is possible if one refrains from conceiving it as a natural object. Through phenomenological reduction, a radically different perspective on subjectivity is attained, one that is committed to the radical opposition between (constituting) subjectivity and (constituted) objectivity, both of which are related to each other in a transcendental "correlational a priori" and accessible to phenomenological reflection.

\section{Natorp and Husserl reconsidered}

Two provisional points should be presented at this stage with regard to this preliminary outline of Husserl's phenomenology and its relation to Natorp's challenge of a reflective investigation of subjectivity.

First, Husserl fully agrees with Natorp's critique of psychology as being a discipline ill-suited to treat its subject matter in a methodologically appropriate way. Indeed, this viewpoint can be found throughout Husserl's complete writings. He reiterates his critique of psychology, for the sake of an example, much later in The Crisis of European Sciences and Transcendental Phenomenology: "Natural human understanding and the objectivism rooted in it will view every transcendental philosophy as a flighty eccentricity, its wisdom as useless foolishness; or it will interpret it as psychology which seeks to convince itself that it is not psychology" (1970a, p. 200). Thus, like Natorp, Husserl rejects psychology since it is, and will be, unable to teach us anything about the proper essence of subjectivity because of two closely related reasons. On the one hand, psychology remains stuck in the naïveté of the naturalistic attitude and consequently fails to recognize the difference between transcendental subjectivity and mundane empirical subjectivity. On the other hand, and as a direct consequence of the first, it has conceived of its object (the "psyche" or the "soul") as something real, similar to any object of the 
natural sciences, and hence follows the path of an objectivistic science more geometrico. In contrast, Husserl resists any characterization of subjectivity in terms used for the characterization of physical objects and hence considers its study according to the methods of natural science a category mistake.

Second, however, it is questionable if Husserl's reconfiguring of phenomenology as a transcendental investigation of subjectivity really solves the radical nature of Natorp's critique. Let us recall that Natorp's critique is in the first place a methodological one, aiming for phenomenology as grounded in reflective intuition. Although it may well be the case that phenomenology no longer considers subjectivity along the lines of the natural sciences, that it attains a transcendental outlook on absolute consciousness and that it refrains from naturalizing it through the phenomenological reduction, the question remains if it is consequently able to avert Natorp's logic according to which, "every Aüsserung is an Entaüsserung," that is, according to which, "subjectivity is objectifying as such." Even more so, to the extent that the description of the by now phenomenologically reduced "pure consciousness" still rests on the evidence-paradigm of reflective intuition, and that the possibility of this description is essential for grounding phenomenology as the transcendental "science of all sciences," the question with regard to the ability of Husserl's transcendental phenomenology to stand up against Natorp's challenge retains its force, even, maybe especially, within the transcendental domain. As Zahavi explains, with respect to the importance for phenomenology as a reflective enterprise of clarifying this problematic within the transcendental domain, "To deny that transcendental subjectivity manifests itself is to deny the possibility of a phenomenological analysis of transcendental subjectivity. And to deny that is to deny the possibility of transcendental phenomenology altogether" $(1999$, p. 51). Indeed, we have seen that the task of a transcendental phenomenology is not merely restricted to a meticulous description of the appearance of the world in all its ontic diversity, but precisely to unearth the appearance qua appearance and its conditions of possibility. When we begin to study the distinguishing features of this appearing, we will notice that it is characterized by an intentional and dyadic structure: appearance is an appearance of something for someone. If we acknowledge this dyadic and intentional structure for the appearance of, for example, tables and chairs, does it then equally hold for the manifestation of transcendental subjectivity itself? To put it differently: can the condition of appearance appear itself? Can that which forms the condition for phenomenal appearance also become a phenomenon in its own turn? Or do we have to reconstruct this dimension, as Natorp suggests, as that "what will have been" starting from the constituted objectivity?

Let us expand on this second point by relating this question to the distinction Husserl draws in his Ideas II between the "pure or transcendental Ego" and the "empirical Ego," alternatively designated as the "empirical subject," the "real psychic Ego," or "I-as-man" (1952/1989, pp. 98-99). As argued by several authors (Bernet, Kern, \& Marbach, 1993; Carr, 1999; Luft, 2010), the appearance of this distinction, and more specifically Husserl's employment of the Kantian notion of the "transcendental or pure Ego," is itself a consequence of Husserl's engagement with the Neo-Kantian tradition and a notable divergence from his earlier work in the Logical Investigations. There, in the first edition of this work (1901-1902/1970b), Husserl had famously declared that he was "quite unable to find" what the Neo-Kantians (and especially Natorp) called the "pure Ego" (p. 92). 
But then, later on, in a much-quoted footnote in the revised second edition of the Logical Investigations published in 1913, Husserl famously declared, partially in response to Natorp's Einleitung in die Psychologie (1888), that he had "since managed to find it" (1913/1970b, p. 353) which, according to Husserl, becomes clear from the considerable analysis he devoted to the topic in the Ideas. Indeed, in clear contradistinction to his earlier opposition, here Husserl firmly argues that "everywhere the distinction must certainly be made between the objectified and the 'originally' not objectified pure Ego, e.g., between the perceived and the perceiving pure Ego" (1952/1989, p. 108). Or, that "we have to distinguish between the 'I that I am' on the subject side and the 'I that I am' as Object for myself, an Object which is, in the existing 'I am,' represented, constituted, and perhaps intended in the specific sense: the me" (Husserl, 1952/1989, p. 265).

Before continuing our analysis of what can be called the "pluralization of the Ego," the obvious first question to be raised here concerns the meaning of Husserl's delayed recourse to this distinction: why or where did Husserl eventually manage to find the pure Ego? Evidently, it would be quite absurd to assert that its sudden emergence would be the outcome of a painstaking investigation into the unknown depths of subjectivity where it suddenly announced itself in all its undeniable glory after having remained concealed from Husserl's introspective gaze in the years before the Ideas. Nor should Husserl's lucky retrieval of the Ego be confused with a delineation of the empirical conditions that are supposed to be fulfilled in order to give rise to consciousness, that is, the empirical person as bearer or ego of conscious experiences, since phenomenology, as we have already made clear, seeks to give an account of the essential structures of consciousness, regardless of the contingent question of which empirical bearer it belongs to. As several authors have noted (Bernet et al., 1993; Zahavi, 1999), the principal reason why Husserl eventually conceded to the Neo-Kantian postulation of the Ego and why he took into consideration, within the phenomenological reduction, the subjective orientation toward an I-subject of these reduced, pure, immanent experiences, was the difficulties that his initial non-egological theory encountered when it came to a phenomenological clarification of the transcendental constitution of the Other. Indeed, an operational condition of possibility for an investigation of the mode of appearance of the Other within transcendental consciousness is quite evidently that one operates with a theory of subjectivity which allows for a demarcation of $m y$ consciousness from that of another. But as long as Husserl's phenomenological analysis restricted itself to an eidetic description of immanent experiences "in a no man's land," that is, with the experience of "no one at all," it proved unable to differentiate between the mode of appearance of my own experience and the experience of the Other as Other, as fundamentally characterized by its transcendent alterity. In sum, it is precisely because conscious experience implies a subject of that experience (i.e., that is $m y$ experience), that a generalized transitivism is warded off within its phenomenological analysis.

If we now follow Husserl's earlier incitation to differentiate between "the objectified and the 'originally' not objectified pure Ego," (1952/1989, p. 108) the obvious Natorpian question to be raised here is consequently about the compatibility between Husserl's methodological "principle of all principles" and this pure being of the Ego. Moreover, if we concede with Husserl that there is indeed more to an analysis of subjectivity than an empirical thematization of how I appear as a mundane entity, as a person or human being 
who seems to be a causally determined thing among other things - in short: as an empirical Ego - the question remains if this is the only way in which I appear to myself as an object. As Husserl argues:

it is in no way correct to assert that the pure Ego is a subject that can never become an Object, as long as we do not limit the concept of Object at the very outset and in particular do not limit it to "natural" Objects, to mundane "real" Objects, for if we do, the assertion would indeed hold in a good and valid sense. (1913/1983, p. 107)

But indeed, let us, in accord with the prescriptions of the phenomenological epoché, not limit the concept of object with regard to the subjective life of the Ego to mundane or empirical objects, and instead, likewise in keeping with the phenomenological clarification of objectivity, redefine the object as that which is intended within the transcendental "correlational a-priori." How then do I appear to myself within this transcendentally reassessed field of appearance? Another way of posing this same question is by relating the issue of transcendental self-appearance to the outcome of phenomenological reflection within this same field of appearance: what is the effect of the reflectional act, by now understood as transcendental reflection, on the "I that I am on the subject side"? Does it remain unaltered throughout the transition from its pre-reflexive state of anonymous functioning to its subsequent thematization within the reflectional act? Or does the act of reflection, as Natorp argues, necessarily and inevitably involve a certain loss vis-à-vis subjectivity as it is lived before the reflection?

Having arrived at this central point of our discussion, it seems we are confronted with two remaining options with regard to the status of phenomenological reflection as the methodological gateway to investigating subjectivity.

First, phenomenological reflection does not alter the pre-reflexive givenness of the original, not objectified Pure Ego and is consequently able to grasp subjectivity in its transcendental functioning. Advocates of this view will either suggest that reflection, rather than being a falsifying mirror which transforms whatever it makes appear (to use Gashé's Derridean phrase: reflection as entailing a "tain in the mirror"), should be regarded as a kind of "disclosing intensification" or "consummation" (Merleau-Ponty, $1945 / 2002$, p. 207) of the pre-reflexively lived experience, or they will appeal to a kind of hierarchization of the reflexive function in terms of a distinction between "pure" or "impure" (Sartre), "radical" and "less radical" (Merleau-Ponty), or "theoretical" and "hermeneutical" (Heidegger) forms of reflection. However, although it could be argued that one should make a distinction between, on the one hand, forms of reflection that explicitly reify and objectify their subject matter in the sense of a naturalistic reduction of subjectivity to the world as prima materia and, on the other hand, reflection in the sense of the phenomenological epoché, one nevertheless cannot argue that reflection $a s$ such simply repeats or continues whatever was already given before the reflection. For if this should be the case, why would we engage in this reflective procedure, whose explicit aim was to lift the dogmatic slumber of the naturalistic self-forgetfulness of subjectivity in the first place? Indeed, if phenomenological reflection simply rejoins what was already known in advance, it would be a superfluous methodological avatar only able to disclose its circular point of departure. 
Second, phenomenological reflection, although it might escape a naturalistic objectification of its subject matter, is itself confronted with what we called earlier "a pluralization of the Ego": a redoubling or splitting of the Ego between a subject of reflection and a reflected subject. As Asemissen points out, every reflexive thematization of subjectivity is necessarily marked by a self-fission or self-multiplication of the subject (1958/1959, p. 262) and, as Zahavi indicates, it is consequently characterized by an "internal division, difference and distance" $(1999$, p. 188). One of the important consequences of this is that reflection, even when purified from its worldly elements, will always and inevitably fall short with regard to subjectivity qua anonymously functioning subject-pole and hence will encounter in itself a structurally inscribed moment of "self-forgetfulness." And although Husserl holds fast on his principle of all principles according to which phenomenology ought to ground its considerations exclusively on what is presented before it in phenomenological reflection, a similar conclusion can be drawn from his writings when he argues that, for example,

the ego that is the counterpart to everything is anonymous. It is not its own counterpart. The house is my counterpart, not vice versa. And yet I can turn my attention to myself. But then this in which the ego comes forward along with everything that was its counterpart is again split. The ego that comes forward as a counterpart and its counterpart [e.g., the house it was perceiving] are both counterparts to me. Forthwith, I- the subject of this new counterpart - am anonymous. (Husserl, 1931/1973, p. 2)

To conclude, although it is evident that there exists a decisive difference between a naturalistic and transcendental-phenomenological reflection at the level of their respective (non-) philosophical understandings of subjectivity (i.e., empirically delineated object-in-the-world vs. transcendental subject-for-the-world), at a more formal levelthat is, irrespective of their subsequent descriptive interpretations of subjectivity - both seem to be confronted with a structural moment of naïveté or forgetfulness which is operationally inscribed within the effort to capture subjectivity reflectively. And although, once again, the nature of what we are inclined to call a structural impossibility within the effort to return to subjectivity is of a very different status depending on a naturalistic or a phenomenological understanding, it is our contention that the dividing self-alienation which arises between the subject of reflection and the reflected subject, and the relation between both, is of crucial importance for every effort to delineate the essence of subjectivity.

In the following final section of this article we will examine how Lacan handles the question of this structural impossibility from the perspective of a psychoanalytic theory of subjectivity and, more in particular, how he does so by means of the distinction that he draws in his 11th Seminar on The Four Fundamental Concepts of Psychoanalysis between "the subject of enunciation" and "the subject of the utterance" (1964/1977).

\section{The Lacanian split subject}

Thus far our discussion of the phenomenological effort to return to subjectivity by means of a transcendentally reduced reflective investigation of consciousness has come across 
a number of themes that can serve as subsequent points of entrance for our elucidation of Lacan's position with respect to this problem. First, we have seen that both Natorp and Husserl, for closely related reasons, are critical of psychology understood as a specialized enterprise, among the numerous established empirical sciences, dedicated to the study of its own province of reality - the human psyche. Second, in spite of their shared rejection of psychology, Natorp and Husserl clearly differ when it comes to the outline of a methodological alternative which is able to meet psychology's diagnosed shortcomings. Natorp's "critical method" tries to side-step the subject's objectification by means of a genetic reconstructive attempt. Ultimately however, an immediate access to this original dimension is deemed structurally unattainable. For Husserl, by contrast, phenomenology's core methodological commitment is strictly linked to the possibility of a reflective thematization of subjectivity, although, as we have seen, the latter should be purified from its naturalistic remainders through the phenomenological epoché. Furthermore, and somewhat at odds with phenomenology's methodological principle, we noted that the phenomenological reduction in its turn does not, so to speak, "reduce" the egological structure which pertains to every reflective act, namely the reflectively induced self-fission or splitting of the subject between an anonymous "subject of reflection," on the one hand, and a thematically "objectified ego" as intended within the reflective act, on the other.

With regard to our first question - that is, Lacan's appreciation of psychology considered as an empirical discipline dedicated to the scientific study of the human psyche-it is clear that, to a large extent, Lacan agrees with Natorp's and Husserl's critical reservations toward psychology and, more in particular, with its inadequacy to give a rigorous account of subjectivity. As Lacan contends in his 1960 piece The Subversion of the Subject and the Dialectic of Desire in the Freudian Unconscious, wherein he sets out his arguments against what he deems the positivistic self-conception of the sciences:

I shall take advantage of your kindness in assuming we agree that a science cannot be conditioned upon empiricism. Secondly, we encounter what has already been constituted, with a scientific label, by the name of psychology. Which I challenge - precisely because, as I will show, the function of the subject, as inaugurated by Freudian experience, disqualifies from the outset what, going by the name "psychology," merely perpetuates an academic framework, no matter how one dresses up its premises. (1960/2006e, p. 672)

Lacan's critique of what can be called, in line with Husserl, "psychology's naturalistic self-understanding" is by now a familiar one: no matter how much psychology selfconfessedly asserts to rely solely on empirical data and unbiased observation, it nevertheless cannot function without a non-empirical foundation as its operational condition of possibility. For Lacan, psychology, in its attempt to don the clothing of the natural, observational sciences, feebly denies its necessary roots in a set of inadequately thematized assumptions-its own disavowed "academic framework." Any psychological school, in order to advance its empirical research, tacitly relies on a series of metaphysical (or, more properly, metapsychological) presuppositions - for example, a conception of the mind-body relation, an understanding of the subject-object distinction, a particular notion of what constitutes consciousness/experience, and so on. These meta-level 
positions support the edifice of "what has already been constituted by the name of psychology" (Lacan, 1960/2006e, p. 672), and yet because of its pretension to be grounded strictly in "the facts themselves" under the banner of its avowed "empiricism," psychology, according to Lacan, "tends to forget the circuitous path by which it came into being; otherwise stated, it forgets the dimension of truth that psychoanalysis seriously puts to work" (1966/2006d, p. 738). Hence, in a quote that could have been easily written by Husserl instead, Lacan concludes: "science, if one looks at it closely, has no memory" (1966/2006d, p.738). Moreover, and further pointing towards a principal agreement between Husserl and Lacan in their respective understanding of the relation between psychology and subjectivity, what is precisely forgotten by scientific psychology is, as Lacan contends, "the function of the subject" (1960/2006e, p. 672).

Lacan's unremitting insistence on the function of the subject as being of central importance to his reworking of psychoanalytic theory in his famous retour à Freud may come as a surprise for both those who, on the one hand, tend to consider Freud's notorious "discovery" of the unconscious as sharply opposed and even antithetical to any philosophical account which stresses the importance of the subject (as the much celebrated story goes, after Copernicus and Darwin, Freud delivered the third and most bitter blow to the subject's narcissistic self-understanding when he showed that "the ego is not even master in its own house") and, on the other hand, those who tend to downplay Lacan as a mere child of his time (e.g., Frank, 1989). That is, the time of a strict and fierce structuralism that seemed to have done away with any notion of the subject whatsoever and once and for all assigned it to its proper place: namely, that of an imaginary epiphenomenon of an underlying determinative "a-subjective" structure functioning "behind" or "beneath" or "anterior" to the subject and at the same time rendering the subject the ignorant place of self-deception, blind to the structures of which it was essentially the outcome (Dolar, 1998). But if so, what then to think of Lacan's call, after his insistence in the beginning of his teaching, on a "return to Freud" in order to avoid the misunderstandings of the ego-psychological obfuscation of the Freudian heritage, for a second "return," yet this time "to Descartes" (1946/2006c, p. 133)? Does this mean that Lacan eventually realized that Freud had perhaps been a little too hasty in his psychoanalytic burial of the self-conscious subject of German philosophy and consequently subscribed to that project with which we already became familiar through our reading of Natorp and Husserl?

As is the case with most philosophical questions worth pondering, the answer is not straightforward. Lacan has, nonetheless, an original take to offer with regard to the possibility to "return to subjectivity" as an alternative for the naturalistic and psychological objectifications, which was the second theme we deduced from the discussion between Natorp and Husserl. Moreover, in both his 11th Seminar (1964/1977) as in the Ecritsarticle, The Subversion of the Subject and the Dialectic of Desire in the Freudian Unconscious (1960/2006e), Lacan resumes the egological structure that was the outcome of the phenomenological reduction, that is, the field of tension surrounding the reflectively induced self-fission of the subject between "subject of reflection - reflected subject," albeit in structuralistic terms, as the difference between the "subject of enunciation" and the "subject of the utterance." What is, according to Lacan, the relation between these two subjects and are we able to circumvent, through a yet unknown methodological 
tour de force, the difference between both in order to accomplish the dazzling task set by both Natorp and Husserl of returning to our most pristine, lived subjectivity? According to Lacan, to put it very simply, we cannot. Moreover, Lacan confirms the irreducible difference between the "subject of enunciation," which tries to represent itself by means of the diachronic chain of unfolding signifiers, and the "subject of the utterance," which is to be regarded as the objectified sense-result of the linguistic closure or, to put it more technically, "punctuation" of the anticipated signification that was set in motion through the use of signifiers (Lacan, 1964/1977, p. 140). Or, as Lacan later formulates this distinction in his 1973 essay L'étourdit, there is an irrevocable difference between the "saying" (dire) of enunciation and the "said" (dit) of the utterance (1973/2001, pp. 452-453). Lacan terms this process, wherein the subject of enunciation tries to represent itself but at the same time necessarily loses itself within language, the "fading" of the subject (1964/2006b, p. 709 ; $1964 / 1977$, p. 208) and provides it with the following definition: "The subject is this emergence which, just before, as subject, was nothing, but which, having scarcely appeared, solidifies into a signifier" (1964/1977, p. 199). Thus far, however, we did not do anything more than provide a reformulation of the foregoing neoKantian and phenomenological analyses within a Lacanian framework: reflection within and throughout the use of language thereby replaced reflection within the intentional act. However, what separates Lacan's account of the preceding analyses is to be read in his following reformulation of the temporal and logical dynamic that inheres in the same process of "fading":

Produced in the locus of the yet-to-be-situated Other, the signifier brings forth a subject from a being that cannot yet speak, but at the cost of freezing him. The ready-to-speak that was to be there-in both senses of the French imperfect "il y avait" placing the ready-to-speak an instant before (it was there but is no longer), but also an instant after (a few moments more and it would have been there because it could have been there) — disappears, no longer being anything but a signifier. (Lacan, 1964/2006b, p. 713)

As is often the case with Lacan, he uses an almost disorientating terminology to describe the process wherein the subject of enunciation is being rewritten or reflected in the form of its linguistic counterpart. Can we make this a bit clearer? The "ready-to-speak that was to be there" can be taken as roughly equivalent to the original subject of enunciation, whereas the subsequent condition of "freezing," or in Natorpian terms, "mortification" stands for the objectified subject of the utterance. Important however is Lacan's additional suggestion that, in this by now familiar process of ongoing "corpsification," there is a fundamental illusion to be aware of: it is not that $\mathrm{I}$, as a fully constituted subject, always-already self-consciously precede or preexist the unfolding of the signifying chain and concomitant process of signifying closure leading to the articulation of the "subject of the utterance," and that I, as Natorp would say, become betrayed by the objectifying dimension of the Entäusserung implied by language use. No, in Lacan's view, this idea that "there was to have been" a pristine subjectivity that is subsequently betrayed by its necessarily flawed translation into the "subject of the utterance" is an après-coup illusion of perspective. Or to put it differently: the ever elusive, nostalgic returning point of fullblown immediacy which allegedly precedes the deplorable Entäusserung of the subject is for Lacan the dynamic outcome (i.e., placing it both "an instant before" as "an instant 
after" the process of reflection) rather than the point of departure, of the fading of the subject. ${ }^{3}$ Furthermore, this paradoxical logic according to which the impediment to reflexive identification simultaneously generates that to which it is an impediment, is the defining feature, or perhaps the Husserlian essence, of Lacanian subjectivity as such. As Slavoj Žižek has noted time and again in his instructive cross-reading of Lacanian psychoanalysis and German Idealism, the Lacanian split subject is the constituted correlate of the failure of its own representation (1998, p. 263). Or to revert to Husserlian terminology: the Lacanian split subject (\$) or subject of the unconscious makes its home within the gap separating the "I that I am on the subject side" and the "I that I am as Object for myself," within the irreducible difference that is operationally inscribed in the very surface of reflexive consciousness itself. This subject is thenceforth no longer, as it has traditionally been conceived, the mysterious outside or negative counterpart of consciousness, residing in some sort of unfathomable depth or irrational container lurking beneath the smooth surface of its transcendental counterpart and secretly pulling the strings, but a performative dimension of subjectivity and correlated outcome of consciousness' inability to close up on itself. Or as Lacan prosaically put it:

Now if, turning the weapon of metonymy against the nostalgia that it serves, I stop myself from seeking any meaning beyond tautology, and if, in the name of "war is war" and "a penny's a penny," I resolve to be only what I am, how can I escape here from the obvious fact that I am in this very act? (1957/2006a, p. 430)

In this very performative act, where I finally renounce every effort to reflexively determine my own identity by retreating in the tautological statement "I am I," hence simultaneously acknowledging that the enunciation of the first I is apparently insufficient to secure my own identity, is where the minimal level of temporal negativity concomitant of the Lacanian subject inevitably makes its entrance.

\section{Conclusion}

We started our discussion by revisiting the contemporary debate on the so-called "explanatory gap" between cognitive and naturalistic explanations of the mind and the firstperson dimension of subjective experience. As has been rightfully argued by several authors, a necessary requirement for the effort to start bridging this gap is to take this first-person perspective seriously in order to grasp adequately what has to be explained in the first place. It is precisely in this effort to get a firm grasp on the "explanandum," that is, what it is like to be a subject with a first-person experience, and in the method we have to employ to investigate this dimension in its own right, that our discussion of Natorp, Husserl, and Lacan obtains its relevance.

First we have seen that Natorp points towards a dimension of subjectivity that eludes every effort to grasp it reflexively. Second, Husserlian phenomenology enables us to avoid the naturalistic objectification of subjectivity - that is, subjectivity as a mere object in the world which is assumed to be amenable to an unproblematic process of empirical individuation and description akin to the measurement of middle-sized, three-dimensional objects in the external world - and instead points towards subjectivity as the transcendental condition from where the empirical world is understood in the 
first place. Furthermore and more importantly, as we have pointed out in our analysis of Husserl's transcendental phenomenology, besides the explanatory gap which separates naturalistic from phenomenological accounts of subjectivity, there is another "gap" which inheres within the reflexive first-person account itself.

In our opinion, it is at this precise point that a productive discussion between phenomenological and Lacanian accounts of subjectivity can take place. Whereas this gap within the reflexive surface of consciousness is traditionally understood as an epistemological stumbling block in our perpetual effort to "return to subjectivity," we have seen that Lacan treats this gap as an ontological dimension of subjectivity which marks and determines our first-person experience as such. To designate the paradoxical nature of such a subject, Lacan famously coined the term "split subject," which he, in a punning reformulation of the Cartesian phrasing, characterized as follows: "I am thinking where I am not, therefore I am where I am not thinking" (1957/2006a, p. 430). This means above all that the very relation it entertains with itself must be rooted in a fundamental impossibility of coinciding with itself. And although this may sound like an odd definition of subjectivity, certainly when placed in the light of the contemporary portrayal of the naturalization debate (cf. infra), it must be remarked that it is also a perfectly classical one: from Hegel to Sartre, passing via Kierkegaard and Heidegger, the subject has long been defined either as an impossible being that is what it is not and is not what it is, or one for whom identity and difference are identical, a paradoxical entity which is at the same time a given and a task, and so on (Maniglier, 2012). Furthermore, we think that such a conception of subjectivity is also consistent with more recent phenomenological readings that emphasize the "internal differentiation" and "immanent alterity" at the very heart of the phenomenon of self-manifestation, at the expense of the usual portrayal of the phenomenological transcendental subject as a self-enclosed entity marked by an unmediated, pure, and apodictic self-presence (Zahavi, 1998).

So, to conclude our discussion, what then are the possible consequences of such a paradoxical definition of the subject as, in the words of Lacan, "caught up in a constituting division" for the contemporary naturalization debate and the explanatory gap-argument we briefly touched upon in our introduction? Although a full exposition of this matter would exceed the limits of this article, we will nevertheless point out what we consider to be two of its most interesting and promising implications in terms of their potential to provide a new perspective on how this debate is currently understood. By this we mean, first, that the Lacanian reformulation of subjectivity in terms of a constitutive "méconnaissance," while at a first glance seeming to undermine our very idea of subjectivity both as it appears to us in our most immediate self-experience and as it is traditionally conceptualized within the phenomenological first-person perspective, that is, as a form of intimate self-acquaintance or immediate self-presence (e.g., Heidegger's notion of Jemeinigkeit), actually reinforces the idea of a subjective first-person dimension that is to be taken seriously in its own right above and beyond certain reductionist strategies for which subjective appearances are indeed merely appearances. It could be argued that it is precisely this overly facile philosophical opposition between reality and appearance that figures predominantly in the contemporary naturalization debate: the former is the domain of neurocognitive research in that it tries to give an account of the naturalistic underpinnings of our manifest self-experience, whereas the latter falls entirely within the jurisdiction of phenomenology as a propadeutic descriptive investigation of "the way things 
appear to me in the way they appear to me." Depending on philosophical allegiance, this peculiar distribution of the reality/appearance-doublet has been taken to mean that (a) the success of neurocognitive science should be measured against its ability to "save" the appearances as they were previously defined in the phenomenological first-person perspective (see Roy et al., 1999) or (b) subjectivity can be entirely reduced to the status of "mere seeming" so that the reality of consciousness will turn out to be independent of the subjective appearance of consciousness (see Dennet, 1993).

What is nevertheless shared by these two seemingly radically opposite research agendas is precisely the assumption that is overturned in the Lacanian approach of subjectivity, that is, the idea that subjective appearances are entirely clear for the subject of those appearances or, to use Searle's formulation, that "where appearance is concerned we cannot make the appearance-reality distinction because the appearance is the reality" (1992, p. 121). When we said earlier that Lacan's contestation of such an effacement of the reality-appearance distinction within the very field of appearances itself, common to both phenomenological and reductionist approaches, actually strengthens rather than undermines the possibility of formulating an adequate account of subjectivity, this is primarily due to the fact that it can account for, and makes room for, the notion of subjective truth; that is, the way things actually seem to me even if they don't seem that way to me. Indeed, it is precisely because I can be wrong about myself with respect to my very subjectivity, that the reduction of subjective appearance as mere appearance is warded off in any subsequent research effort to give a naturalistic explanation of subjectivity.

This brings us to our second and last point: if the contemporary naturalization project aims at closing the gap between neurocognitive levels of explanation and the first-person dimension of subjective experience, the somewhat transcendental question we can ask with regard to this effort becomes the following one: what must the ontology of our neurocognitive organization be, so that subjects which are decentered from themselves can emerge as an effect of that level of organization? Although it may seem that such a question is fundamentally at odds with how psychoanalysis today in general responds to - to use the accustomed turn of phrase - "the latest advances in brain sciences," that is, by proclaiming to be the last safe haven for the subject in its non-reducible singularity against the objectifying clutches of all too greedy neuroscientists (for a recent example of this strategy, see Laurent, 2014). However, contrary to this worn-out theme of strategic sacralization of the subject against the ongoing scientific disenchantment of the world, it could be argued that it was precisely this question which stood at the forefront of Lacan's structuralistic retour à Freud. As has been noted by Maniglier (2012), it was Lacan's original idea that this paradoxical element always at a distance from itself, viz. the split subject, far from being only accessible through a transcendental philosophical a priori approach, could be approached scientifically by the then in vogue "structural methods" in the field of the human sciences. And although space prevents us from fully substantiating this claim by, for example, pointing out the similarities and divergences between neurocognitive and structuralistic approaches to the question of subjectivity, it is our view that this question remains one of the most fruitful to investigate in the years to come.

\section{Declaration of Conflicting Interests}

The author(s) declared no potential conflicts of interest with respect to the research, authorship, and/or publication of this article. 


\section{Funding}

This research received no specific grant from any funding agency in the public, commercial, or not-for-profit sectors.

\section{Notes}

1. Natorp's analysis with regard to this skewed relationship between subjectivity and objectivity anticipates, on a transcendental level, similar conclusions that are drawn more recently within the field of analytic philosophy of mind regarding the possibility of reconciling first-person and third-person perspectives on subjectivity by, most notably, Thomas Nagel. Like Natorp, Nagel argues that there will always be an aspect of subjectivity that for fundamental reasons will exceed the limits of objectification (1986, pp. 25-27).

2. However, as Heidegger rightfully pointed out in response to Natorp's critique of phenomenological reflection, re-construction is of course itself also a form of objectivating construction and is therefore susceptible to the same criticism Natorp offers towards phenomenology (Heidegger, 1919/1982, pp. 104-107). For a further reading of the discussion between Heidegger and Natorp and the former's methodological defense of hermeneutical intuition to escape this deadlock, see Zahavi (2003).

3. A possible phenomenological rejoinder to such a conception of the dynamic process that in Lacan's view provides the basic structure of the subject's self-relating is the following one: if we concede to Lacan's view that there is indeed an irreducible difference between the subject of enunciation and the subject of the utterance, and furthermore, that this difference is constitutive of Lacanian subjectivity as such insofar as it is marked by a temporal self-relating negativity, how then are we able to explain the experiential phenomenon that, despite this fracture in the heart of subjectivity, I nonetheless remain the same throughout this process of failed translation? To put this differently, what remains to be explained in such a conception of subjectivity where it is considered the dynamic outcome of a reflexive failure is twofold: (a) the irreducible "my-ness" of subjective experience that is the basic feature of subjectivity within a phenomenological account and (b) the experiential (or other) standard against which reflection is precisely to be considered as a failed reflection. This last question is akin to the critique offered by Manfred Frank in his analysis of Lacan in "What is Neo-Structuralism?" (1989, pp. 279-294). Without going into further detail, we had preferred to see Žižek, in his response to Frank's critique, actually engage with this crucial issue instead of simply "staring at this line of argumentation" (see Žižek, 1998, p. 271).

\section{References}

Asemissen, H. U. (1958/1959). Egologische reflexion [Egological reflection]. Kant-Studien, 50, $262-272$.

Bernet, R., Kern, R., \& Marbach, E. (1993). An introduction to Husserlian phenomenology. Evanston, IL: Northwestern University Press.

Carr, D. (1999). The paradox of subjectivity. Oxford, UK: Oxford University Press.

Cohen, H. (1977). Werke [Works] (H. Holzhey, Ed.). Hildesheim, Germany: Olms.

Dennet, D. C. (1993). Consciousness explained. London, UK: Penguin Books.

De Preester, H. (2006). Naturalism and transcendentalism in the naturalization of phenomenology. New Ideas in Psychology, 24, 41-62.

Dolar, M. (1998). Cogito as the subject of the unconscious. In S. Žižek (Ed.), Cogito and the unconscious (pp. 11-40). Durham, NC: Duke University Press.

Flanagan, O. (1992). Consciousness reconsidered. Boston, MA: MIT Press. 
Frank, M. (1989). What is neostructuralism? (S. Wilke \& R. Gray, Trans.). Minneapolis: University of Minnesota Press.

Gallagher, S. (2002, February). Phenomenology and experimental design: Four approaches. Invited lecture presented at the Brain and Cognition Seminar, Aarhus University Hospital, Denmark.

Gallagher, S., \& Varela, F. J. (2001). Redrawing the map and resetting the time: Phenomenology and the cognitive sciences. In S. Crowell, L. Embree, \& S. J. Julian (Eds.), The reach of reflection: Issues for phenomenology's second century (pp. 17-43). West Hartford, CT: Electron Press.

Gallagher, S., \& Zahavi, D. (2012). The phenomenological mind (2nd ed.). London, UK: Routledge.

Heidegger, M. (1982). The basic problems of phenomenology (A. Hofstadter, Trans.). Bloomington: Indiana University Press. (Original work published 1919)

Husserl, E. (1960). Cartesian meditations: An introduction to phenomenology (D. Cairns, Trans.). The Hague, the Netherlands: Martinus Nijhoff.

Husserl, E. (1970a). The crisis of European sciences and transcendental phenomenology: An introduction to phenomenological philosophy (D. Carr, Trans.). Evanston, IL: Northwestern University Press.

Husserl, E. (1970b). Logical investigations (J. N. Findlay, Trans.). New York, NY: Humanities Press. (Original work published 1901-1902 and 1913)

Husserl, E. (1973). Zur Phänomenologie der Intersubjektivität: Dritter Teil. 1929-1935 [The phenomenology of intersubjectivity: Vol. 3. 1929-1935]. In I. Kern (Ed.), Husserliana XV. The Hague, the Netherlands: Martinus Nijhoff. (Original work published 1931)

Husserl, E. (1983). Ideas pertaining to a pure phenomenology and to a phenomenological philosophy: First book (F. Kersten, Trans.). The Hague, the Netherlands: Martinus Nijhoff. (Original work published 1913)

Husserl, E. (1989). Ideas pertaining to a pure phenomenology and to a phenomenological philosophy: Second book. Studies in the phenomenology of constitution (R. Rojcewicz \& A. Schuwer, Trans.). Dordrecht, the Netherlands: Kluwer. (Original work published 1952)

Husserl, E. (1997). Psychological and transcendental phenomenology and the confrontation with Heidegger (1927-1931) (T. Sheehan \& R. E. Palmer, Trans.). Dordrecht, the Netherlands: Kluwer Academic. (Original work published 1925)

Kim, A. (2007). Recollecting the soul: Natorp's construction of a Platonic "psychology". Internationale Zeitschrift für Philosophie, 16(2), 159-175.

Lacan, J. (1977). The seminar of Jacques Lacan: Book XI. The four fundamental concepts of psycho-analysis, 1964 (J.-A. Miller, Ed.; A. Sheridan, Trans.). New York, NY: W. W. Norton. (Original work published 1964)

Lacan, J. (2001). L'étourdit. In J.-A. Miller (Ed.), Autres ecrits (pp. 449-495). Paris, France: Editions du Seuil. (Original work published 1973)

Lacan, J. (2006a). The instance of the letter in the unconscious. In J. Lacan \& J.-A. Miller (Eds.) \& B. Fink (Trans.), Ecrits (pp. 412-444). New York, NY: W.W. Norton. (Original work published 1957)

Lacan, J. (2006b). Position of the unconscious. In J. Lacan \& J.-A. Miller (Eds.) \& B. Fink (Trans.), Ecrits (pp. 703-721). New York, NY: W.W. Norton. (Original work published 1964)

Lacan, J. (2006c). Presentation on psychical causality. In J. Lacan \& J.-A. Miller (Eds.) \& B. Fink (Trans.), Ecrits (pp. 123-160). New York, NY: W.W. Norton. (Original work published 1946)

Lacan, J. (2006d). Science and truth. In J. Lacan \& J.-A. Miller (Eds.) \& B. Fink (Trans.), Ecrits (pp. 726-745). New York, NY: W. W. Norton. (Original work published 1966)

Lacan, J. (2006e). The subversion of the subject and the dialectic of desire in the Freudian unconscious. In J. Lacan \& J.-A. Miller (Eds.) \& B. Fink (Trans.), Ecrits (pp. 671-702). New York, NY: W.W. Norton. (Original work published 1960)

Laurent, E. (2014). Lost in cognition: Psychoanalysis and the cognitive sciences. London, UK: Karnac Books. 
Luft, S. (2010). Reconstruction and reduction: Natorp and Husserl on method and the question of subjectivity. In R. A. Makkreel \& S. Luft (Eds.), Neo-Kantianism in contemporary philosophy (pp. 59-91). Bloomington: Indiana University Press.

Maniglier, P. (2012). Acting out the structure. In P. Hallward \& K. Peden (Eds.), Concept and form: Vol. 2. Interviews and essays on the cahiers pour l'analyse (pp. 25-46). London, UK: Verso Books.

Merleau-Ponty, M. (2002). Phenomenology of perception (P. Kegan, Trans.). London, UK: Routledge. (Original work published 1945)

Nagel, T. (1986). The view from nowhere. Oxford, UK: Oxford University Press.

Natorp, P. (1888). Einleitung in die Psychologie nach Kritischer Methode [Introduction to psychology according to the critical method]. Freiburg, Germany: J. C. B. Mohr.

Natorp, P. (1912). Allgemeine psychologie nach kritischer Methode [General psychology according to the critical method]. Tübingen, Germany: J. C. B. Mohr.

Parnas, J., Sass, L. A., \& Zahavi, D. (2013). Rediscovering psychopathology: The epistemology and phenomenology of the psychiatric object. Schizophrenia Bulletin, 39(2), 270-277. doi: $10.1093 / \mathrm{schbul} / \mathrm{sbs} 153$

Rinofner-Kreidl, S. (2005). The limits of representationalism: A phenomenological critique of Thomas Metzinger's self-model theory. Synthesis Philosophica, 40(2), 355-371.

Roy, J. M., Petitot, J., Pachaud, B., \& Varela, F. J. (1999). Beyond the gap: An introduction to naturalizing phenomenology. In J. Petitot, F. J. Varela, B. Pachaud, \& J. M. Roy (Eds.), Naturalizing phenomenology (pp. 1-82). Stanford, CA: Stanford University Press.

Searle, J. (1992). The rediscovery of the mind. Cambridge, MA: MIT Press.

Strawson, G. (1997). The self. Journal of Consciousness Studies, 4(5/6), 405-428.

Zahavi, D. (1998). The fracture in self-awareness. In D. Zahavi (Ed.), Self-awareness, temporality and alterity: Central topics in phenomenology: Vol. 34 (pp. 21-40). Dordrecht, the Netherlands: Kluwer Academic.

Zahavi, D. (1999). Self-awareness and alterity: A phenomenological investigation. Evanston, IL: Northwestern University Press.

Zahavi, D. (2003). How to investigate subjectivity: Natorp and Heidegger on reflection. Continental Philosophy Review, 36, 155-176.

Zahavi, D. (2010). Naturalized phenomenology. In S. Gallagher \& D. Schmicking (Eds.), Handbook of phenomenology and cognitive science (pp. 2-19). Dordrecht, the Netherlands: Springer.

Žižek, S. (1998). The Cartesian subject versus the Cartesian theather. In S. Žižek (Ed.), Cogito and the unconscious (pp. 247-274). Durham, NC: Duke University Press.

\section{Author biographies}

Jasper Feyaerts, MSc, is a clinical psychologist and PhD-researcher in the Department of Psychoanalysis and Clinical Consulting at Ghent University (Belgium). His research interests include Lacanian and Freudian Psychoanalysis, psychoanalytic research into psychopathology, continental philosophy of science, philosophy of mind, and phenomenology. Email: Jasper. Feyaerts@UGent.be

Stijn Vanheule, $\mathrm{PhD}$, is a clinical psychologist, psychoanalyst in private practice (affiliated with the Dutch-speaking Kring voor Psychoanalyse of the New Lacanian School), and associate professor in the Department of Psychoanalysis and Clinical Consulting at Ghent University (Belgium). His research interests include Lacanian and Freudian psychoanalysis, psychoanalytic research into psychopathology, psychoanalytically informed clinical psychodiagnostics, and the methodological fields of qualitative research and small sample research. He is the author of multiple papers in these fields of interest. Email: Stijn.Vanheule@UGent.be 